\title{
Morphological and Molecular Study of Hybrid Oncocytic/Chromophobe Tumor of the Kidney Associated with Sporadic Renal Oncocytosis and Chronic B-Cell Lymphocytic Leukemia: The Possible Contribution of Lymphoma to Renal Oncocytosis
}

\author{
Miguel A. Idoate ${ }^{\mathrm{a}}$ Inmaculada Trigo ${ }^{\mathrm{a}} \quad$ Jesús Saenz de Zaitigui ${ }^{\mathrm{b}}$ \\ Manuel Pérez-Pérez ${ }^{a} \quad$ Juan José Ríos ${ }^{a}$ \\ aPathology, University Hospital Virgen Macarena, University of Seville, Sevilla, Spain; ${ }^{b}$ Radiology Department, \\ University Hospital Virgen Macarena, University of Seville, Sevilla, Spain
}

\section{Established Facts}

- Hybrid oncocytic/chromophobe tumor (HOCT) of the kidney is currently a subset of tumors with overlapping histology between renal oncocytoma and chromophobe renal-cell carcinoma.

- HOCT arising from oncocytosis not associated with the Birt-Hogg-Dubé syndrome is an unusual and highly interesting neoplasm.

- Experimental and clinical findings suggest that renal oncocytosis may arise in relation with toxins or chronic kidney failure, but other possible causes are not known.

\section{Novel Insights}

- In this work, we show the potential role of lymphoma in the development of oncocytosis and pose interesting questions about pathogenesis.

- Based on our immunohistochemical and molecular results, we think that HOCT is closer to the oncocytoma than the chromophobe tumor.

- Molecular analysis of the HOCT revealed AKT3 gene mutation, which is classified as probably pathogenic, and FOS1 gene amplification.

\section{Keywords}

Hybrid oncocytoma/chromophobe tumor - Oncocytosis . Lymphoma

\begin{abstract}
Hybrid oncocytic/chromophobe tumor (HOCT) of the kidney arising from a precursor oncocytosis not associated with the Birt-Hogg-Dubé (BHD) syndrome is an unusual and highly interesting neoplasm. Immunohistochemical and
\end{abstract}

Correspondence to:

Miguel A. Idoate, midoate@us.es 
molecular findings suggest that HOCT is an entity distinct from both oncocytoma and chromophobe carcinoma. Although uncertainty persists regarding the factors predisposing to the development of $\mathrm{HOCT}$, experimental findings suggest that it may arise due to the effect of toxins or in association with chronic kidney failure. The potential role of prior renal lymphoma in the development of oncocytosis has not hitherto been examined. We present a morphological, immunohistochemical, and molecular analysis of an HOCT arising from renal oncocytosis in conjunction with $C L L$ affecting the kidney. The findings suggest that this tumor belongs to a family of similar neoplasms including oncocytoma, the eosinophilic variant of chromophobe renalcell carcinoma (CRCC), and low-grade oncocytic tumor, even though these neoplasms may arise from different precursor lesions. HOCT and oncocytosis revealed the same immunohistochemical profile consistent on positivity for epithelial membrane antigen (EMA), cytokeratin 7 (Ck7), E-cadherin, CAM 5.2 and negativity for Pax-8, vimentin, renal-cell carcinoma (RCC) antigen, $C D 117$, racemase, progesterone receptor, and CD10. The Ki-67 proliferation index was $<1 \%$. Molecular analysis of the tumor revealed the AKT3 gene mutation variant, classified as probably pathogenic, together with FOS1 gene amplification and no copy number variations (CNVs). Finally, we present a case of HOCT arising from a nonhereditary renal oncocytosis in conjunction with $B$ lymphoma that raises interesting questions regarding pathogenesis.

(c) 2021 S. Karger AG, Basel

\section{Introduction}

Hybrid oncocytic/chromophobe tumor (HOCT) is a rare renal neoplasm currently classified as a variant of chromophobe renal-cell carcinoma (CRCC) [1]. In morphological terms, HOCT strongly resembles oncocytoma, from which it differs essentially in the presence of perinuclear halos and frequent binucleation [2, 3]. Though the sporadic form is the most common, HOCT has also been reported in a hereditary setting, in association with Birt-Hogg-Dubé (BHD) syndrome [4] Sporadic HOCT may arise from renal oncocytosis, that is, the diffuse proliferation in the kidney of oncocytic epithelial cells originating in the renal collecting tubules [5]. The precise causes of renal oncocytosis are yet unknown, although it has been associated both with chemical carcinogens and with chronic kidney failure [6,7]. We report on an unusual sporadic HOCT associated with oncocytosis in conjunction with a previously diagnosed B-cell lym- phoma of the kidney. Morphological and molecular findings are discussed, together with the potential role of Bcell lymphoma as a factor predisposing to the development of HOCT.

\section{Case Report/Case Presentation}

A 72-year-old male was diagnosed with B-cell CLL (Binet Stage A) in 2009 and is currently undergoing standard cyclophosphamide-fludarabine-rituximab chemotherapy, with continued clinical follow-up. MRI follow-up showed no changes in the abdominal CT in 2012. In CT scan of the left kidney, in 2014, a small image appeared in the cortex of less than $5 \mathrm{~mm}$. In the retrospective review of the CT scan of 2012, there was no visible injury. In 2015, the patient displayed multiple swollen lymph nodes (retroperitoneal, mesenteric, mediastinal, pelvic, hilar, and axillary). In addition, CT scan revealed a solid cortical nodule $20 \mathrm{~mm}$ in the left kidney in diameter, isodense relative to the renal parenchyma, and showing low contrast uptake. A further CT scan in February 2019 disclosed the solid nodule measuring $24 \mathrm{~mm}$. In 2020, 2 solid nodules were identified, 1 in each renal pole, the higher of $27 \mathrm{~mm}$ in diameter. No significant radiological changes were observed in the right kidney. Contrast-enhanced MRI revealed 2 solid masses showing heterogeneous enhancement on administration of i.v. contrast; the masses, measuring 28 and $25 \mathrm{~mm}$, respectively, were hypointense on T1-weighted and iso-hypointense on T2-weighted images, and showed increased contrast uptake in the portal phase (shown in Fig. 1). Renal function was conserved. Small splenic nodules were also observed, together with numerous swollen retroperitoneal, mesenteric, and pelvic lymph nodes. Patient history included psoriasis and colon carcinoma in 2000. The patient was a nonsmoker with no relevant family history. No skin or lung lesions were apparent. A left radical nephrectomy was performed. No lymph nodes were removed from the surgical specimen.

The nephrectomy specimen comprised a kidney measuring 10 $\times 6 \times 5 \mathrm{~cm}$, together with adjacent pericapsular fat and a $2-\mathrm{cm} \mathrm{seg-}$ ment of the ureter. There were no grossly apparent changes on the kidney surface. Examination of serial sections revealed 3 separate well-circumscribed nodular lesions of elastic consistency, light brown in color, and of maximum width $3.5,1.5$, and $0.3 \mathrm{~cm}$; these nodules did not extend to the capsule or renal sinus (shown in Fig. 2).

Histopathological examination disclosed 3 tumors of similar morphological appearance, together with multiple nodular lesions not discernible at gross examination, and numerous nests of cells sharing similar features. These proliferating oncocyte-like cells were surrounded by an atypical lymphoid infiltrate (shown in Fig. 3). The 3 large tumor-like nodules were expansive, well-circumscribed but not encapsulated, and bore a strong histological resemblance to oncocytomas. Nodules were composed of cells with eosinophilic granular cytoplasm and rounded nuclei with finely dispersed chromatin, inconspicuous nucleoli, and clear perinuclear halos. Irregular "raisinoid" nuclei characteristic of CRCC were not detected. Binucleation was common. There was no evidence of atypia, necrosis, or mitotic activity, nor any invasion of blood or lymph vessels or sarcomatoid transformation. Despite multifocal partial transformation of renal tubular epithelium into oncocytic epithelium with a metastatic appearance, the general ar- 


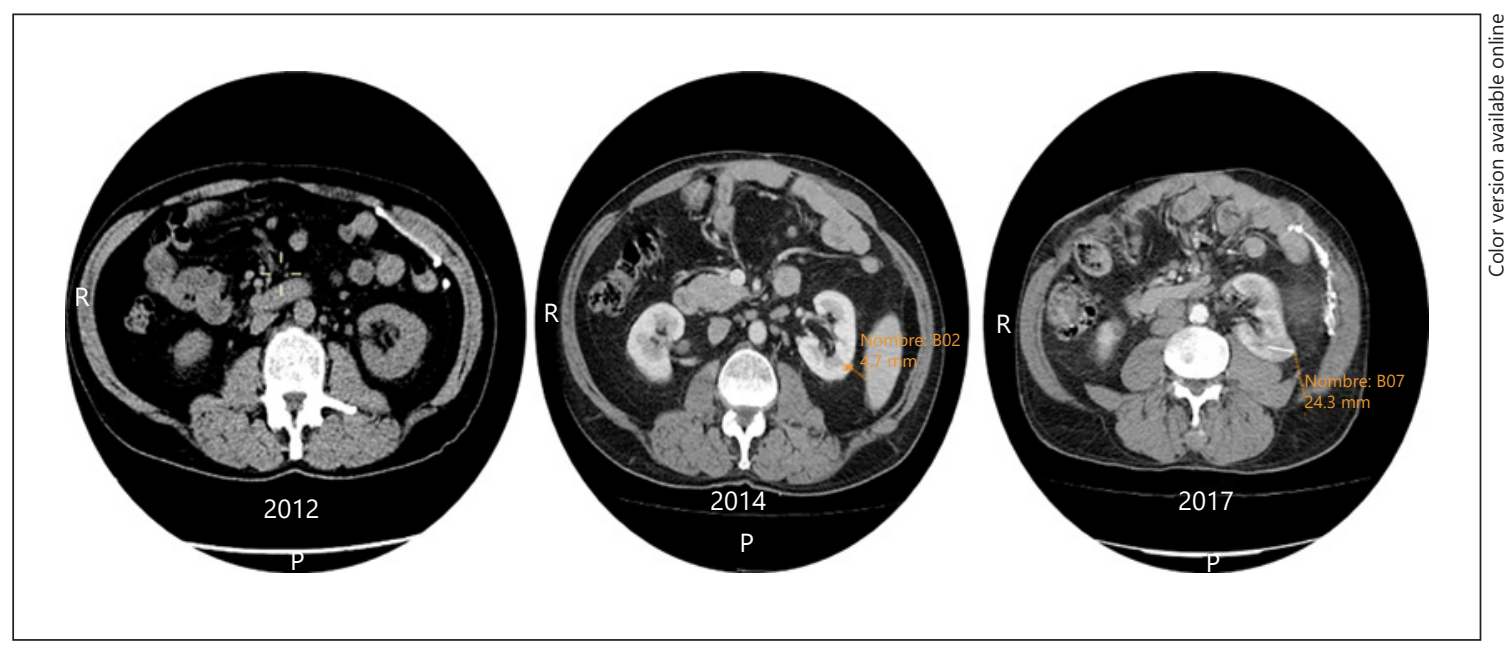

Fig. 1. Evolution of the left kidney tumoral nodule by CT images (period 2012-2017): in the first image of 2012, there was no visible injury; in 2014, a small image appears in the cortex of less than $5 \mathrm{~mm}$, which changes to 24 $\mathrm{mm}$ in 2017.

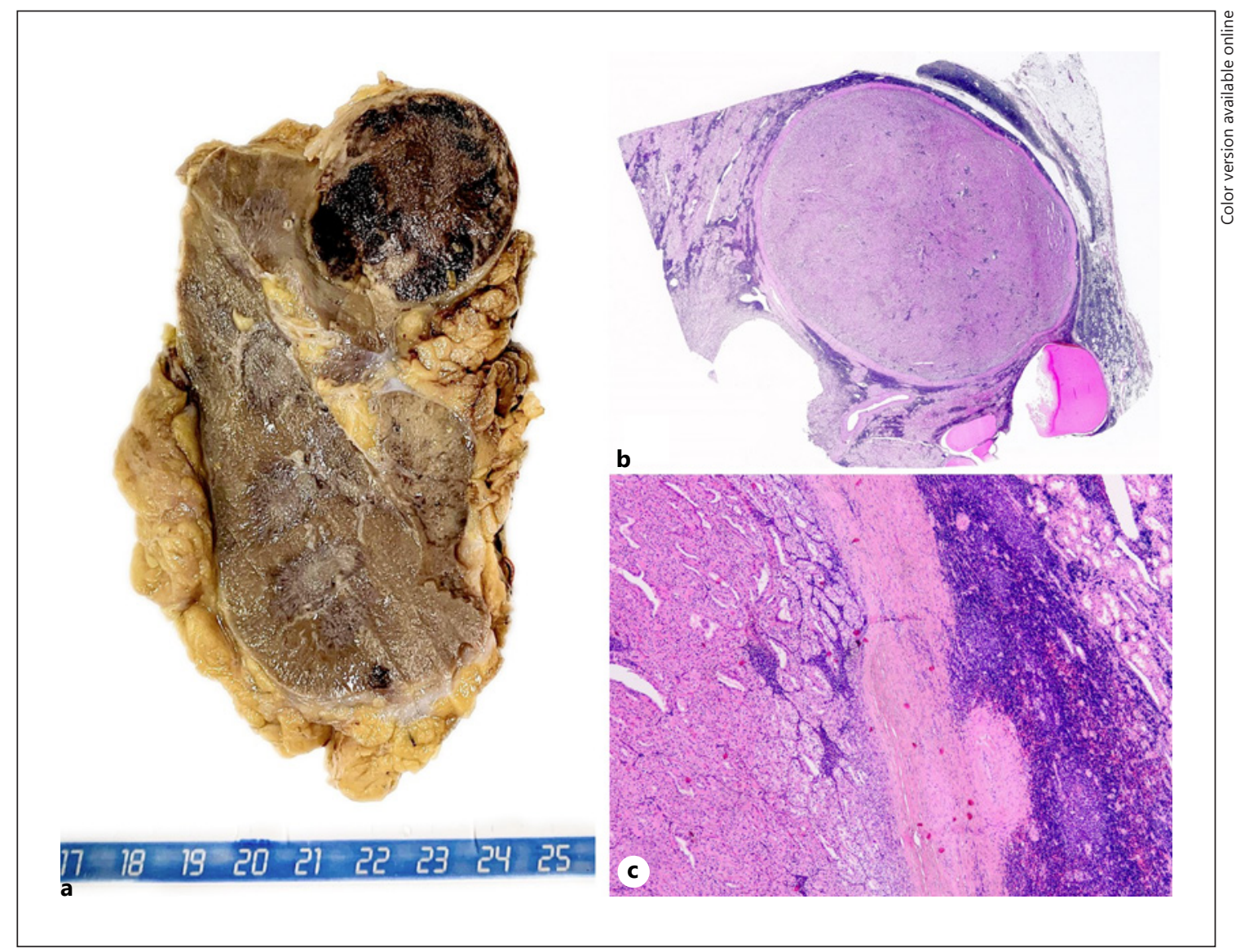

Fig. 2. a Macroscopy of highest nodular tumor expansive and well-circumscribed light brown in color. b A large expansive, well-circumscribed and oncocytic tumor nodule partially encapsulated is observed. $\mathrm{H}$ and $\mathrm{E}$, panoramic. c Tumor is separated from the rest of parenchyma by a fibrous tract. The dense lymphoma is observed around of and inside the tumor. H\&E. $\times 100$. 


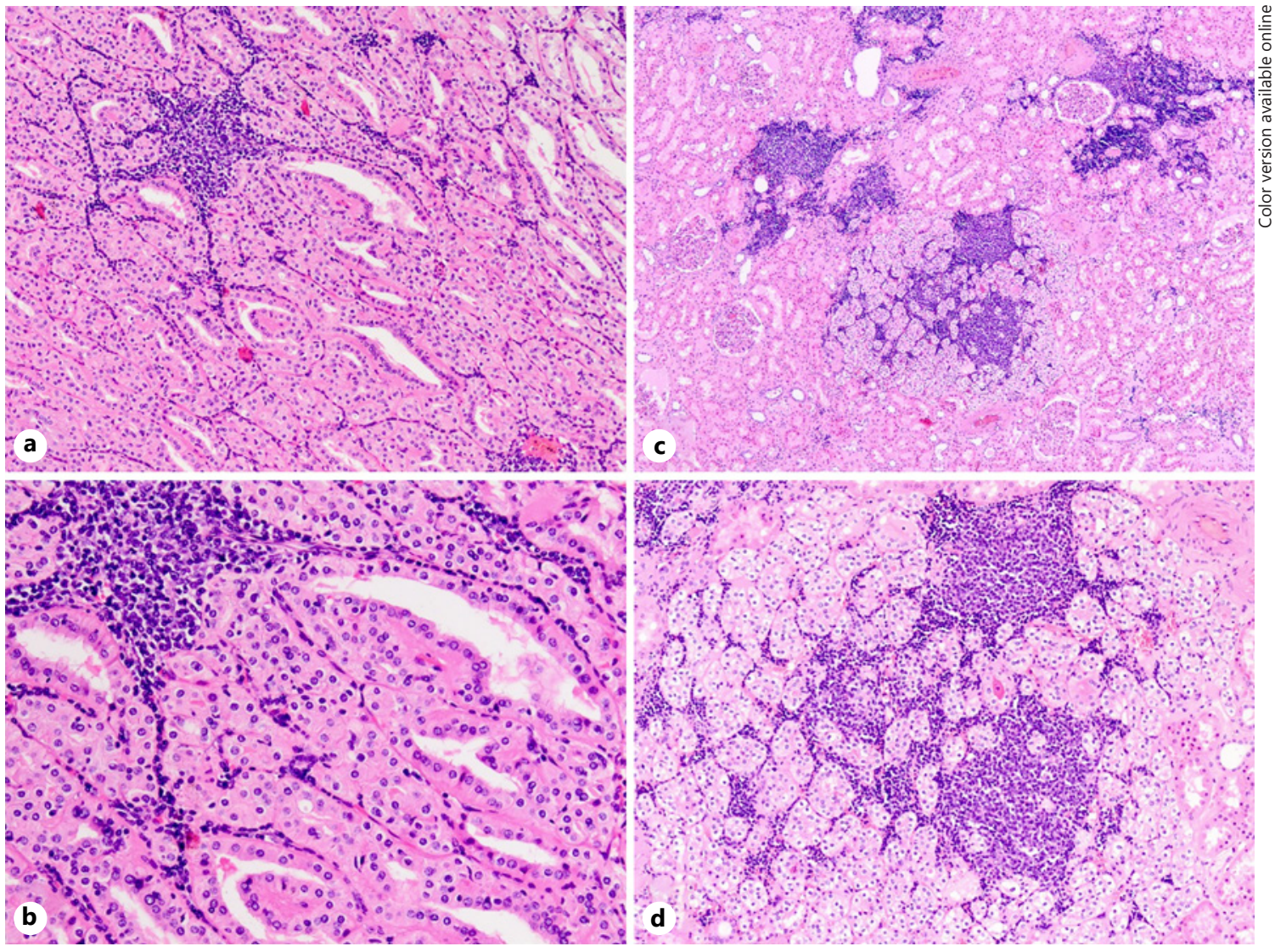

Fig. 3. Histological view of the 1 oncocytic nodule. Dense aggregate of oncocytic cells with more or less evident luces are seen. The dense atypical infiltrate is observed inside the nodule. No atypia, necrosis, or mitotic activity is observed (a), H and E. $\times 100$. Tumoral nodules were composed of cells with eosinophilic granular cytoplasm and rounded nuclei with finely dispersed chromatin, inconspicuous nucleoli, and clear perinuclear halos. Irregular "rai- sinoid" nuclei are not observed. Binucleation was common. (b). H\&E. $\times 200$. Multifocal infiltrative lymphoma with associated oncocytic transformation of renal tubular epithelium with preservation of the general architecture of adjacent renal parenchyma (c), H\&E. $\times 100$. Incipient oncocytic lesions were embedded in an atypical lymphoid infiltrate (d), H\&E. $\times 200$. chitecture of renal tubules was conserved. Strikingly, oncocytic nests and incipient oncocytic lesions were embedded in an atypical lymphoid infiltrate. Other findings included cortical cysts, some lined by a single layer of oncocytic cells, several small papillary adenomas displaying calcifications, and occasional cortical fibromas.

Immunohistochemical analysis of tumors and oncocytic epithelial proliferations revealed positive staining for epithelial membrane antigen (EMA), with an apically reinforced cytoplasmic expression pattern. Staining for cytokeratin 7 (Ck7) was positive in some areas and negative in others. In positive-staining areas, $\mathrm{Ck} 7$ expression was not homogeneous; negative cells were intermingled with positive cells displaying varying cytoplasmic staining intensity. Expression of E-cadherin and CAM 5.2 was also observed (shown in Fig. 4). The Ki-67 proliferation index was $<1 \%$. Tumor cells were negative for Pax-8, vimentin, renal-cell carcinoma (RCC) antigen, CD117, racemase, progesterone receptors, and CD10.

Atypical lymphoid infiltrate was identified throughout the renal parenchyma in a multifocal pattern, extending beyond the cap- sule into perirenal adipose tissue. Infiltrate was composed of relatively small monomorphic atypical lymphoid cells with occasional blasts forming discrete proliferative clusters. Tumor lymphoid cells stained positive for bcl-2, CD20, CD5, and CD79alpha; and negative for bcl-6, CD10, MUM-1, and cyclin D1. Ki-67 expression in proliferative clusters was focally $60 \%$ (shown in Fig. 5). The immunohistochemical profile of the lymphoid infiltrate matched that observed in a previous lymph-node biopsy. The diagnosis was kidney involvement of a B-cell chronic lymphoid leukemia/small cell lymphocytic lymphoma.

Molecular analysis based on high-throughput sequencing revealed the variant c.973C > T (p. Arg325Ter) at exon 10 of the AKT3 gene, classified as probably pathogenic, together with FOS1 gene amplification. No copy number variations (CNVs) were observed, except for a gain on chromosome 12 (shown in Fig. 6). The final diagnosis was multiple HOCT of the kidney associated with oncocytosis (mpT1a, Nx) in conjunction with renal involvement by a chronic lymphoid leukemia/well-differentiated B-cell lymphoma. 


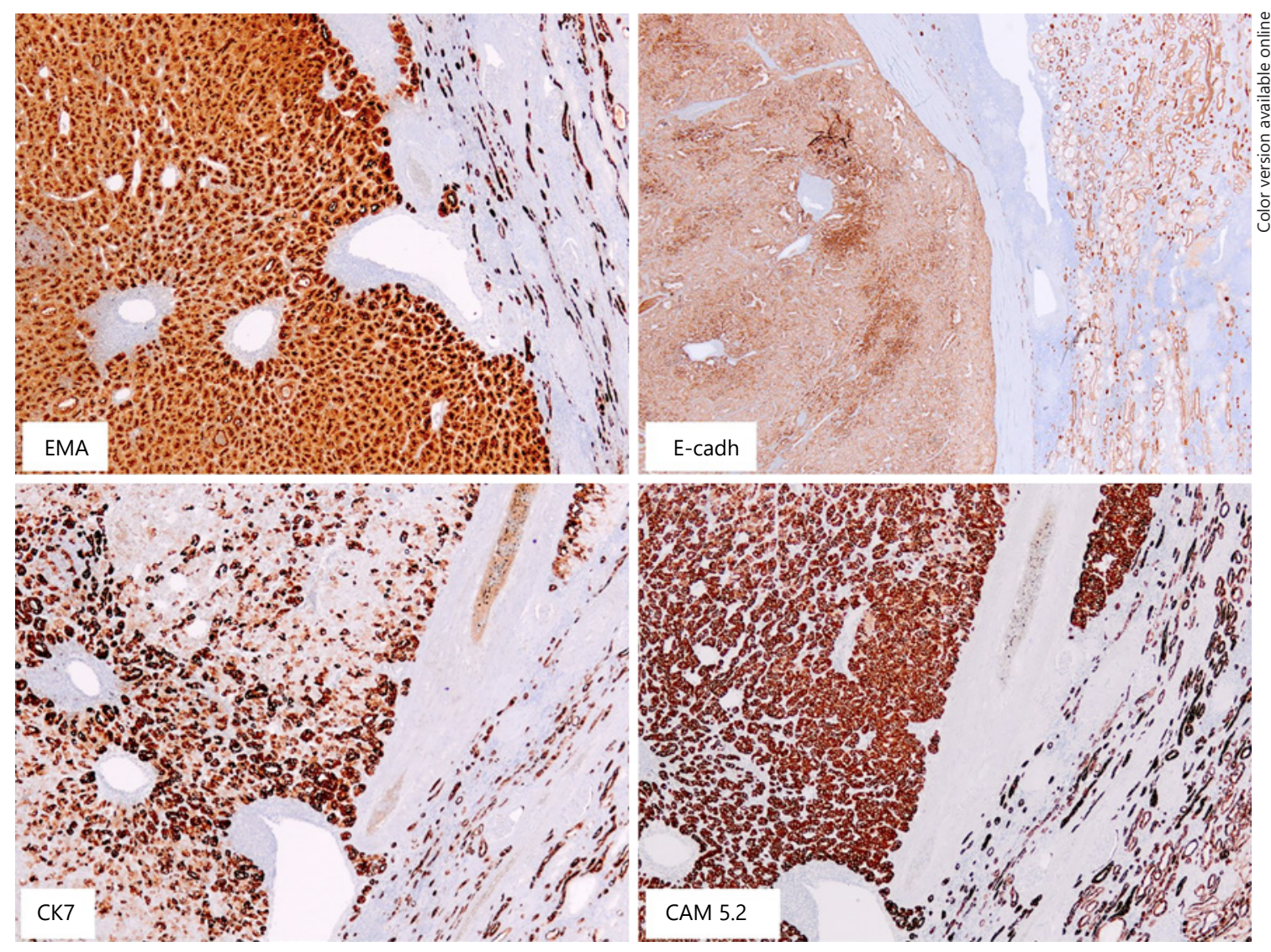

Fig. 4. Immunohistochemical analysis revealed positive staining for EMA, with an apically reinforced cytoplasmic expression pattern. Staining for $\mathrm{Ck} 7$ in positive-staining areas was not homogeneous; negative cells were intermingled with positive cells display- ing varying cytoplasmic staining intensity. Expression of E-cadherin and CAM 5.2 were both intense and diffuse. EMA, epithelial membrane antigen; Ck7, cytokeratin 7.

\section{Discussion/Conclusion}

HOCT has been reported in 3 clinical settings: as a sporadic tumor; in association with renal oncocytosis; and as a component of BHD syndrome, an autosomal dominant inherited condition caused by mutations in the gene coding for folliculin (FLCN) and characterized by the lung and skin lesions (fibrofolliculomas). Sporadic oncocytosis-associated HOCT and its BHD-related counterpart share certain common features: both arise from a precursor lesion termed renal oncocytosis, and in both cases neoplasms tend to be multifocal and bilateral [4]. Sporadic and hereditary HOCTs are invariably benign $[1,4$, 5]. Renal oncocytosis often affects both kidneys, and is generally asymptomatic. HOCT arising from renal oncocytosis is a rare neoplasm mostly reported in adults non-BHD oncocytosis usually affecting elderly patients - and gender distribution is almost equal.

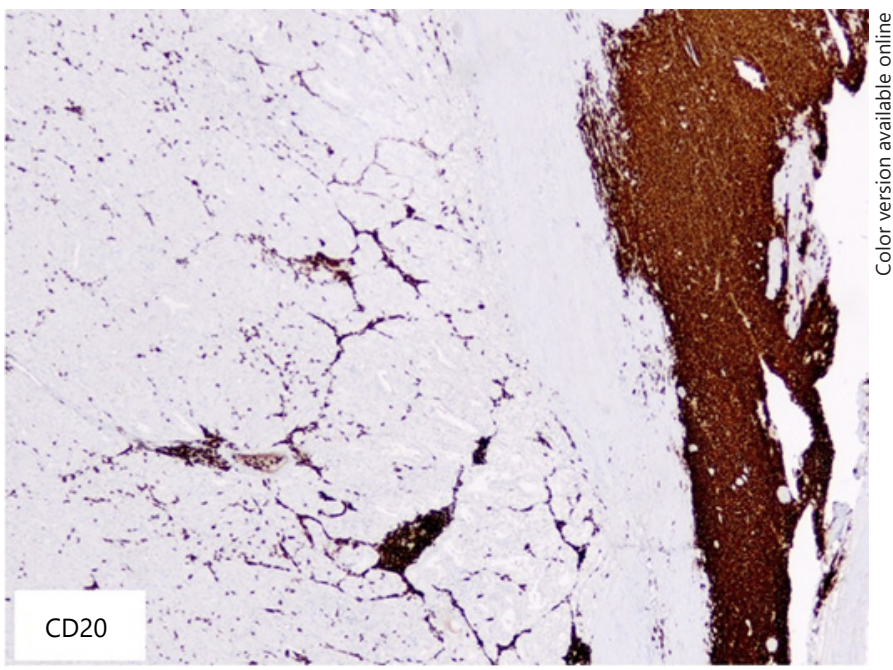

Fig. 5. Tumor lymphoid cells corresponding to a B-CLL/B lymphoma well-differentiated inside and outside the epithelial tumoral nodule stained positive for CD20, $\times 100$. 


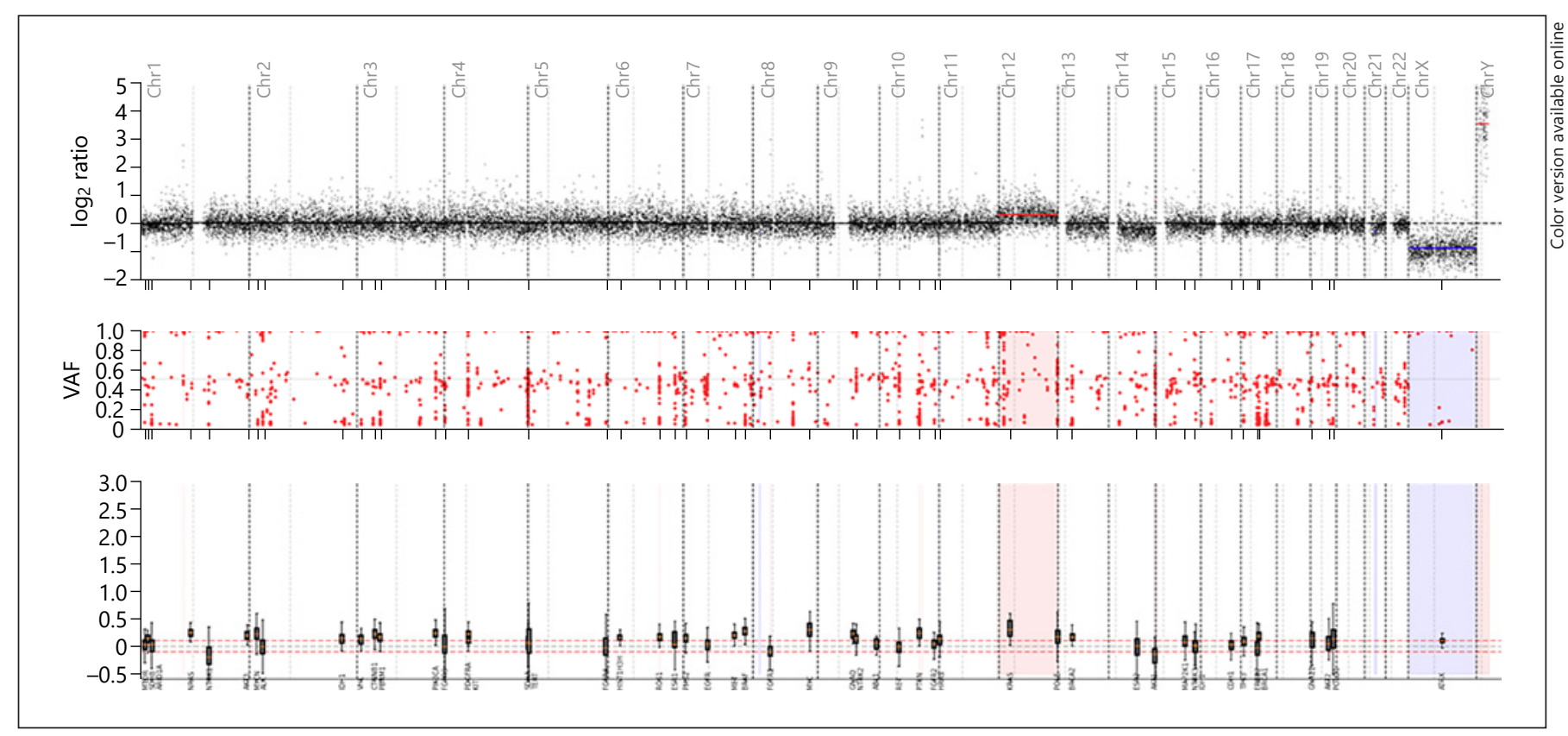

Fig. 6. No CNVs were observed, except for a gain on chromosome 12 in the molecular analysis. CNVs, copy number variations.

Renal oncocytosis has been defined as diffuse involvement of the kidney by a gradual proliferation of oncocytic epithelial cells originating in the collecting ducts, leading to the development of oncocytic tumors. The process thus spans a lesional spectrum ranging from initial oncocytic changes in renal tubules with scarcely any alteration of nephron architecture, through the presence of hyperplastic-like nests of oncocytic cells to the formation of dominant nodules of neoplastic appearance [8]. Lesions may be innumerable and affect the entire renal parenchyma. Tumors arising in this context are mostly HOCTs, although oncocytomas and CRCCs are also reported in this setting. Several authors have even suggested that oncocytomas may progress to CRCCs [9]. It would seem more likely, as Tickoo et al. [5] have noted that HOCTs - like oncocytomas and CRCCs - arise through the progressive transformation of oncocytic nests, as was clearly apparent in this case. It is thus unsurprising that oncocytic tumors should present with another overlapping spectrum of lesions with varying morphologies.

The kidney affected by oncocytosis also tends to display other, non-oncocytic, lesions - such as the papillary adenomas observed here - although, as other authors have reported, these are probably chance findings. One interesting feature of the present case was the appearance of cortical cysts partially lined by an oncocytic epithelium.
HOCTs are currently classified as a subset of tumors with overlapping histology between renal oncocytoma (RO) and chromophobe RCC[1]. Yet, the morphology of HOCT closely resembles that of oncocytoma, from which it differs only in minor aspects such as the appearance of perinuclear halos. Cytological differences with respect to CRCC are more marked. One proof of the singular status of HOCT is the joint presence of Ck7-positive and Ck7negative cells. Ck7 expression tends to be negative in RO and positive in CRCC. Here, positive-staining areas alternated with negative areas; even within Ck7-positive areas, staining was by no means homogeneous, since negative cells intermingled with positive cells displaying varying cytoplasmic staining intensity.

However, this intermediate expression was not recorded for other markers (shown in Table 1): immunostaining for c-Kit and Pax8 was negative for HOCT but is positive in both CRCC and RO [10-12], while for the other markers tested, HOCT displayed staining similar to that of the other tumor types [13]. The expression of certain markers provides pointers to the histogenetic origin of these oncocytic tumors. Interestingly, E-cadherin and racemase expression would suggest that tumor cells in HOCT, RO, and CRCC share a common origin in the renal collecting ducts. Indeed, positive staining in renal oncocytosis would support the view that $\mathrm{RO}$ also originates in the collecting ducts [14-18]. In the present study, pos- 
Table 1. Comparative morphological, immunophenotypic, and molecular features of HTOC, oncocytoma, and chromophobe carcinoma

\begin{tabular}{|c|c|c|c|c|}
\hline $\begin{array}{l}\text { Phenotypic/ } \\
\text { immunohistochemical/ } \\
\text { molecular features }\end{array}$ & \multicolumn{2}{|l|}{ HTOC RCC } & Sporadic oncocytoma & $\begin{array}{l}\text { Sporadic chromophobe } \\
\text { carcinoma }\end{array}$ \\
\hline Phenotype & \multicolumn{2}{|c|}{$\begin{array}{l}\text { Oncocytoma-like, but perinuclear halos, no } \\
\text { atypia, no mitosis, no necrosis }\end{array}$} & $\begin{array}{l}\text { Oncocytic, round } \\
\text { nuclei, no atypia }\end{array}$ & $\begin{array}{l}\text { Oncocytic, polygonal } \\
\text { "plant-like" cell with a } \\
\text { distinct cell membrane } \\
\text { raisinoid nuclei, atypia }\end{array}$ \\
\hline AMACR & \multicolumn{2}{|l|}{ Negative } & Negative & Negative \\
\hline Vimentin & \multicolumn{2}{|l|}{ Negative or positive } & $\begin{array}{l}\text { Negative or focally } \\
\text { positive }\end{array}$ & Negative \\
\hline Cadherin-E & \multicolumn{2}{|l|}{ Positive, cytoplasmic } & & Positive \\
\hline c-Kit & \multicolumn{2}{|l|}{ Negative } & Positive & Positive \\
\hline Pax8 & \multicolumn{2}{|l|}{ Negative } & Positive & Positive \\
\hline $\mathrm{Ck} 7$ & \multicolumn{2}{|c|}{ Positive and negative, variable intensity } & Negative & $\begin{array}{l}\text { Positive, cytoplasmic, } \\
\text { intense positivity }\end{array}$ \\
\hline Molecular & \multirow{2}{*}{\multicolumn{2}{|c|}{ Polisomies and monosomies. CNV }} & \multirow{2}{*}{$\begin{array}{l}\text { Polisomies and } \\
\text { monosomies }\end{array}$} & \multirow{2}{*}{$\begin{array}{l}\text { Polisomies and } \\
\text { monosomies }\end{array}$} \\
\hline Cytogenetic alterations & & & & \\
\hline Molecular & $\begin{array}{ll}\text { Sporadic HTOC } & \text { Hereditary } \\
\text { associated to } & \text { HTOC in the } \\
\text { oncocytosis } & \text { BHD }\end{array}$ & $\begin{array}{l}\text { Sporadic } \\
\text { HTOC no } \\
\text { oncocytosis/ } \\
\text { no BHD }\end{array}$ & & \\
\hline
\end{tabular}

BHD, Birt-Hogg-Dubé syndrome; FLCN, folliculin; HTOC RCC, hybrid tumor oncocytoma/chromophobe renal-cell carcinoma; $\mathrm{CNV}$, copy number variation; EMA, epithelial membrane antigen; Ck7, cytokeratin 7.

itive staining for $\mathrm{Ck} 7$ and for EMA indicated a combination of the expression profile of the principal cells in the collecting ducts with that of the intercalated cells. Expression of Ck7, with apical membranous staining for EMA but no cytoplasmic staining, would appear to be characteristic of collecting-duct principal cells, whereas negative staining for $\mathrm{Ck} 7$ and intense positive cytoplasmic staining for EMA is characteristic of intercalated cells [19]. No previously published reports have highlighted this singular apically enhanced cytoplasmic staining pattern for EMA in HOCTs, which may well be a distinctive feature enabling the hybrid tumor to be differentiated from both $\mathrm{RO}$ and chromophobe RCC.

Since HOCTs arise in 3 different clinical settings, molecular changes might be expected to differ in each case, even though morphological features may be similar. HOCT associated with BHD syndrome [20] is characterized by germline mutations in the FLCN gene which are not observed in HOCTs arising in the other settings. Similarly, this mutation is not found in sporadic oncocytomas or in CRCCs, whether or not associated with oncocytosis, but has been reported in those arising within the context of BHD syndrome [20].

A further interesting consideration is that mitochondrial DNA mutations are common in oncocytoma, in CRCC [21] and in focal oncocytosis; they are likely to be present in HOCT, too, although this has yet to be determined. Mitochondrial DNA mutations may account for mitochondrial proliferation as a compensation mechanism in all 3 tumor types. 
No studies have yet compared cytogenetic changes in the 2 groups of sporadic HOCTs. In those not associated with oncocytosis, cytogenetic anomalies such as monosomies and polysomies have been observed, particularly in chromosomes 1, 14, 20-1 of the most widely affected-21, and Y $[3,12]$; by contrast, little research has focused on cytogenetic changes in HOCTs associated with renal oncocytosis [22]. The gain on chromosome 12 observed here has not been reported previously.

The molecular expression profile of sporadic HOCT differs from that of both oncocytoma and CRCC [23]. Though closer to that of oncocytoma in terms of CNVs, low mutational load, absence of mutations in driver genes, and cytogenetic aberrations [23,24], its molecular expression profile is clearly different. HOCT also differs considerably from CRCC not only in molecular expression but also in the molecular and chromosomal changes indicated earlier $[23,25]$. In molecular terms, therefore, HOCT may be regarded as closer to oncocytoma than to CRCC $[3,12,24,26]$.

The AKT3 gene mutation observed here is known to induce cell growth and proliferation and enhance apoptosis resistance. To the authors' knowledge, this is the first report of the mutation in HOCT of the kidney. Interestingly, the PTEN, TERT, and TP53 gene mutations typical of CRCC and the ERCC2 mutation characteristic of RO [23] were not observed in the present case. The absence of CNVs and the low mutational load indicate a genetic profile closer to that of RO.

With regard to the pathogenesis of HOCT, renal oncocytosis is clearly the precursor lesion in a large number of cases [26]. Oncocytosis in patients with BHD syndrome may be attributed to germline mutations in the FLCN gene [4] encoding FLCN protein, which is expressed in the distal tubule and collecting duct. It has been argued that FLCN acts as a tumor suppressor gene, and that its mutation may induce expression of the potent angiogenic trigger hypoxia-inducible factor 1-alpha, thus favoring tumorigenesis. However, the FLCN gene mutation is not observed in renal oncocytosis arising in a nonhereditary context. Although the cause of non-BHD oncocytosis is unknown, oncocytomas have been experimentally induced in rats treated with certain chemical carcinogens, including $\mathrm{N}$-nitrosomorpholine [6]. In a clinical setting, oncocytosis has been reported in patients with chronic kidney failure and those undergoing dialysis $[7,27]$. The patient under study here had no history either of contact with carcinogens or of chronic kidney failure.

A striking feature of the case presented here was the concurrent presentation of oncocytosis and infiltration of the renal parenchyma by B-cell lymphoma. Whether the lymphoma may have triggered the development of oncocytosis remains a matter of speculation. Reports of histopathological findings in lymphoma-affected kidneys make no mention of oncocytosis, although sample sizes were very small. In 2 clinical series comprising a total of 54 patients with lymphoma B diagnosed by percutaneous kidney biopsy, 18 of whom had CLL/well-differentiated Blymphocyte lymphoma, no evidence was reported of oncocytic changes in renal tubules $[28,29]$. In an additional case report of a $\mathrm{RO}$ associated to oncocytosis in a patient previously diagnosed of B-cell small lymphocytic lymphoma, no atypical lymphoid infiltration was observed in the nephrectomy surgical specimen [30]. Even so, 2 findings in the present case point to the possible contribution of lymphoma to oncocytosis. First, a close topographical relationship was observed between initial oncocytic lesions and atypical lymphoid infiltrate, although it was not possible to determine whether this was a causal relationship or simply reflected a particular tropism of atypical lymphoid cells for previously developing areas of oncocytosis. Second, radiological evidence shows that the kidney involvement developed progressively between 6 and 10 years after diagnosis of chronic lymphoid leukemia. However, it is impossible to determine whether oncocytosis developed naturally and independently of the renal lymphoma.

The differential diagnosis of HOCT should include other eosinophilic kidney tumors, and particularly the eosinophilic variant of clear-cell carcinoma, angiomyolipoma, the eosinophilic variant of CRCC [25], the oncocytic variant of CRCC [22], and low-grade oncocytic tumor [31]. The first 2 differ considerably from HOCT in terms of morphology and immunohistochemical features, and should thus pose no particular diagnostic challenge. In most cases, HOCT displays slight morphologi$\mathrm{cal}$, immunophenotypic, and molecular differences with respect to eosinophilic CRCC [32], itself a heterogeneous variant not associated with any single morphological pattern $[23,26]$. The main differences are the irregular nuclei and intense c-Kit and Ck7 expression observed in eosinophilic CRCC, although these findings would not alone justify their classification as distinct entities. The oncocytic variant of CRCC shares certain morphological and immunophenotypic features with HOCT. To add to the confusion, Trpkov et al. (2019) [31] recently reported on a "low-grade oncocytic tumor of the kidney," not associated with either oncocytosis or the BHD syndrome, which displayed morphological and immunohistochemical features very similar to those of HOCT, particularly in terms of intense diffuse positive staining for Ck7. In fact, the 
eosinophilic variant of CRCC, this low-grade oncocytic tumor of the kidney and HOCT would appear to be, in essence, the same entity, forming part of a spectrum of tumors probably arising from a common precursor lesion and with overlapping histological characteristics.

To conclude, this article reports on a hybrid tumor arising from a nonhereditary renal oncocytosis in conjunction with $B$ lymphoma that raises interesting questions regarding pathogenesis. This tumor bore a clear morphological resemblance to the eosinophilic and oncocytic variants of CRCC and to a recently reported low-grade oncocytic tumor of the kidney, suggesting that all these tumors may form part of a spectrum belonging to the same family of neoplasms, deriving from renal oncocytic epithelial proliferation arising in different clinical contexts.

\section{Statement of Ethics}

All procedures performed in this study were in accordance with the ethical standards of the Hospital Ethics Committee and with the 1964 Helsinki Declaration. Written informed consent was obtained from the patient for publication of this case report.

\section{Conflict of Interest Statement}

The authors have no conflicts of interest to declare.

\section{Funding Sources}

No funding was received for this publication.

\section{Author Contributions}

Miguel A. Idoate performed the histological examination of the kidney, did the proposal of the pathogenesis, and was a major contributor in writing the manuscript. Jesús Saenz de Zaitigui analyzed and interpreted the patient radiological data. Manuel PérezPérez performed the macroscopy. Juan Jose Rios obtained the microscopical photographs. Inmaculada Trigo helped us in the molecular study. All authors read and approved the final manuscript.

\section{References}

1 WHO. Classification of tumors of the urinary system and male genital organs. Lyon: International Agency for Research on Cancer; 2016.

2 Delongchamps NB, Galmiche L, Eiss D, Rouach Y, Vogt B, Timsit MO, et al. Hybrid tumour 'oncocytoma-chromophobe renal cell carcinoma' of the kidney: a report of seven sporadic cases. BJU Int. 2009 May;103(10):1381-4.

3 Petersson F, Gatalica Z, Grossmann P, Perez Montiel MD, Alvarado Cabrero I, Bulimbasic $\mathrm{S}$, et al. Sporadic hybrid oncocytic/chromophobe tumor of the kidney: a clinicopathologic, histomorphologic, immunohistochemical, ultrastructural, and molecular cytogenetic study of 14 cases. Virchows Arch. 2010; 456(4):355-65.

4 Pavlovich CP, Walther MM, Eyler RA, Hewitt SM, Zbar B, Linehan WM, et al. Renal tumors in the Birt-Hogg-Dubé syndrome. Am J Surg Pathol. 2002;26(12):1542-52.

5 Tickoo SK, Reuter VE, Amin MB, Srigley JR, Epstein JI, Min KW, et al. Renal oncocytosis: a morphologic study of fourteen cases. Am J Surg Pathol. Sep1999;23(9):1094-101.

6 Nogueira E, Bannasch P. Cellular origin of rat renal oncocytoma. Lab Invest. 1988;59(3): $337-43$.

7 Shiga Y, Suzuki K, Tsutsumi M, Ishikawa S, Gotoh M, Shimokama T, et al. Renal oncocytomatosis in a long-term hemodialysis patient treated by laparoscopic surgery. Int J Urol. 2002;9(11):646.
8 Delahunt B, Eble JN, Egevad L, Yaxley J, Thunders M, Samaratunga H. Emerging entities of renal cell neoplasia. Surg Exp Pathol. 2019;2(1):1-7.

9 Al-Saleem T, Cairns P, Dulaimi EA, Feder M, Testa JR, Uzzo RG. The genetics of renal oncocytosis: a possible model for neoplastic progression. Cancer Genet Cytogenet. 2004 Jul 1; 152(1):23-8.

10 Hu Y, Hartmann A, Stoehr C, Zhang S, Wang $\mathrm{M}$, Tacha $\mathrm{D}$, et al. PAX8 is expressed in the majority of renal epithelial neoplasms: an immunohistochemical study of 223 cases using a mouse monoclonal antibody. J Clin Pathol. 2012;65(3):254-6.

11 Huo L, Sugimura J, Tretiakova MS, Patton KT, Gupta R, Popov B, et al. C-kit expression in renal oncocytomas and chromophobe renal cell carcinomas. Hum Pathol. 2005;36(3): 262-8.

12 Mikami S, Kuroda N, Nagashima Y, Ohe C, Hayashi H, Mizuno R, et al. Classification of solid renal tumor with oncocytic/eosinophilic cytoplasm: is hybrid oncocytic/chromophobe renal tumor a subtype of oncocytoma, chromophobe renal cell carcinoma, or a distinct tumor entity? Ann Transl Med. 2019;7(Suppl 8):S350.

13 Iczkowski KA, Czaja RC. Eosinophilic kidney tumors: old and new. Arch Pathol Lab Med. 2019;143(12):1455-63.
14 Liu L, Qian J, Singh H, Meiers I, Zhou X, Bostwick DG. Immunohistochemical analysis of chromophobe renal cell carcinoma, renal oncocytoma, and clear cell carcinoma: an optimal and practical panel for differential diagnosis. Arch Pathol Lab Med. 2007;131(8): 1290-7.

15 Hes O, Michal M, Kuroda N, Martignoni G, Brunelli M, Lu Y, et al. Vimentin reactivity in renal oncocytoma: immunohistochemical study of 234 cases. Arch Pathol Lab Med. 2007;131(12):1782-8.

16 Tani T, Laitinen L, Kangas L, Lehto VP, Virtanen I. Expression of E- and N-cadherin in renal cell carcinomas, in renal cell carcinoma cell lines in vitro and in their xenografts. Int $J$ Cancer. 1995 Dec 20;64(6):407-14.

17 Langner C, Ratschek M, Rehak P, Schips L, Zigeuner R. Expression of MUC1 (EMA) and E-cadherin in renal cell carcinoma : a systematic immunohistochemical analysis of 188 cases. Mod Pathol. 2004;1:180-8.

18 Geramizadeh B, Ravanshad M, Rahsaz M. Useful markers for differential diagnosis of oncocytoma, chromophobe renal cell carcinoma and conventional renal cell carcinoma. Indian J Pathol Microbiol. 2008 Apr-Jun; 51(2):167-71.

19 Bonsib SM. Renal Anatomy and Histology, en Heptinstall's Pathology of the Kidney. 6th ed. Filadelfia: Lippincott; 2007. p. 49-56. 
20 Schmidt LS, Linehan WM. Molecular genetics and clinical features of Birt-Hogg-Dubé syndrome. Nat Rev Urol. 2015;12(10):55869.

21 Lang M, Vocke CD, Merino MJ, Schmidt LS, Linehan WM. Mitochondrial DNA mutations distinguish bilateral multifocal renal oncocytomas from familial Birt-Hogg-Dubé tumors. Mod Pathol. 2015;28(11):1458-69.

22 Kuroda N, Tanaka A, Ohe C, Mikami S, Nagashima Y, Sasaki T, et al. Review of renal oncocytosis (multiple oncocytic lesions) with focus on clinical and pathobiological aspects. Histol Histopathol. 2012;27(11): 1407-12.

23 Ruiz-Cordero R, Rao P, Li L, Qi Y, Atherton D, Peng B, et al. Hybrid oncocytic/chromophobe renal tumors are molecularly distinct from oncocytoma and chromophobe renal cell carcinoma. Mod Pathol. 2019;32(11): 1698-707.

24 Poté N, Vieillefond A, Couturier J, Arrufat S, Metzger I, Delongchamps NB, et al. Hybrid oncocytic/chromophobe renal cell tumours do not display genomic features of chromophobe renal cell carcinomas. Virchows Arch. 2013;462(6):633-8

25 Gobbo S, Eble JN, Delahunt B, Grignon DJ, Samaratunga H, Martignoni G, et al. Renal cell neoplasms of oncocytosis have distinct morphologic, immunohistochemical, and cytogenetic profiles. Am J Surg Pathol. 2010 May;34(5):620-6.

26 Davis CF, Ricketts CJ, Wang M, Yang L, Cherniack AD, Shen $\mathrm{H}$, et al. The somatic genomic landscape of chromophobe renal cell carcinoma. Cancer Cell. 2014;26(3):319-30.

27 Nagashima Y, Mitsuya T, Shioi KI, Noguchi S, Kishida T, Hamano A, et al. Renal oncocytosis. Pathol Int. 2005;55(4):210-5.

28 Li SJ, Chen HP, Chen YH, Zhang LH, Tu YM, Liu ZH. Renal involvement in non-hodgkin lymphoma: proven by renal biopsy. Plos One. 2014;9(4):e95190.

29 Corlu L, Rioux-Leclercq N, Ganard M, Decaux O, Houot R, Vigneau C. Renal dysfunc- tion in patients with direct infiltration by Bcell lymphoma. Kidney Int Rep. 2019;4(5): 688-97.

30 Mazzucchelli R, Cheng L, Lopez-Beltran A, Scarpelli M, Montironi R. Renal oncocytosis and multiple papillary adenomas with oncocytoma as dominant nodule coexisting with papillary carcinoma in a patient with diabetic glomerulosclerosis, acquired renal cystic disease and B cell lymphoma. APMIS. 2008 Oct; 116(10):934-8.

31 Trpkov K, Williamson SR, Gao Y, Martinek P, Cheng L, Sangoi AR, et al. Low-grade oncocytic tumor of kidney (CD117-negative, cytokeratin 7-positive): a distinct entity? Histopathology. 2019;75(2):174-84.

32 Amin MB, Paner GP, Alvarado-Cabrero I, Young AN, Stricker HJ, Lyles RH, et al. Chromophobe renal cell carcinoma: Histomorphologic characteristics and evaluation of conventional pathologic prognostic parameters in 145 cases. Am J Surg Pathol. 2008; 32(12):1822-34. 